\title{
DEVELOPMENT OF THE FARM MACHINERY STATISTICAL MANAGEMENT SYSTEM BASED ON WEB
}

\author{
Xindan $\mathrm{Qi}^{1}$,Hua $\mathrm{Li}^{2}$, Wenqing Yin ${ }^{2, *}$ \\ ${ }^{1}$ College of Mechanical and Power Engineering , Nanjing University of Technology, \\ Nanjing, Jiangsu Provice,P.R.China 210009 \\ ${ }^{2}$ College of Engineering, Nanjing Agriculture University, Nanjing ,Jiangsu Provice, P.R. \\ China 210031 \\ * Corresponding author,Address:College of Engineering Nanjing Agricultural University, \\ Nanjing 210031 Jiangsu province,P.R.china.Tel:+86-25-58606607,Fax:+86-25-58606585, \\ E-mail:lihua@njau.edu.cn
}

Abstract: The farm machinery statistics is an important task of the farm machinery management, the statistics of farm machinery in Jiangsu Province are very wide. Improving the working of statistical analyses by advanced computer technology, enhancing the efficiency, is a topic which the farm machinery superintendent and the scientific and technical worker explore continuously. The present situation of the farm machinery statistics management informationization was analyzed .Mainly, the status of the farm machinery statistics management in Jiangsu Province was investigated. Subsequently, the farm machinery statistics management system based on the Web database was developed and the introduction on main function of the system was made.

Key words: farm machinery, statistics, management information system, B/S mode

\section{INTRODUCTION}

Agricultural machinery statistics is one of the important tasks of agricultural machinery management. The data is the main basis for the governmental decision-making. With the development of the computer hardware and software, the application of advanced technology have made it

Please use the following format when citing this chapter:

Qi, X., Li, H. and Yin, W., 2009, in IFIP International Federation for Information Processing, Volume 294, Computer and Computing Technologies in Agriculture II, Volume 2, eds. D. Li, Z. Chunjiang, (Boston: Springer), pp. 1309-1317. 
possible that we can develop an efficient and convenient application which has drawn the attention of the domestic scholars (Guosheng, 1998) . Yao Zhong, from Beijing Agro-business Management University ,came up with the thought of distributed agricultural statistical information, and has explored it theoretically (Zhong, 1995) ; The application, named agricultural mechanization computer management and application of experts consulting system, designed by Hebei Provincial farm machinery management station, and Lanfang civic Agriculture and Forestry Science College and China University of Agriculture ,has passed the evaluation of the experts organized by the Department of the Agriculture in 1995.And most functions of the application has been used by the Mechanization Office of Department of Agriculture and other national concerned branches of farm machinery management of with a satisfying effect[1]. He Yong, from Zhejiang University ,developed a system of farm mechanization database management on the microcomputer according to the design principle of management information system and applying the method of systems engineering and mathematics, which is to meet the need of agricultural mechanization data processing (Yong et al., 1995) . He Ruiyin, from Nanjing Agricultural University, together with his colleagues, developed an farm machinery statistics system, which is a convenient system based on Windows interface, and suitable to the agricultural cultivating system in Jiangsu province. The system can meet the need of the informatization management of the provincial farm machinery statistics (Ruiyin, 1998). As the main participator, I developed a system of agricultural machinery statistics management based on Windows platform, which target at the provincial agricultural cultivating system (Xindan et al., 2000). The Agricultural Mechanization Office of the Department of Agriculture put an agricultural mechanization statistical system into use, which is based on PC and developed by $\mathrm{PB}$, which can be used in data input, transportation and storage. To the upper layer of the managerial object, just import the statistical data disc reported by the various areas. Thus the system brings convenience to the statistical job for the manager. But during the data transporting process, it is still necessary to mail the floppy disk or transport the file and then import the data to the upper system by certain person.

All those application of these systems have greatly increased the efficiency of the agricultural machinery management, and saved numerous manpower and material. But the reported examples are all single-user systems which can not meet the need of the digitalized and informationized society. There are disadvantages such as low efficient, lagged information and errors during the transporting and disposing the data. Therefore developing such a management system based on Browser/Server to realize the distributed management through network is of rich practical value. (Singh et al., 1994) 


\section{SYSTEM ANALYSES}

There are 13 prefecture-level cities in the province of Jiangsu at present. Report forms of agricultural machinery from various regions are reported to the upper layer in the forms of paper and floppy disk. The statistical working conference is held each year. The agricultural machinery bureaus from various cities are asked to attend. According to the investigation and analysis about the system, we can get the flow chart of operational information.

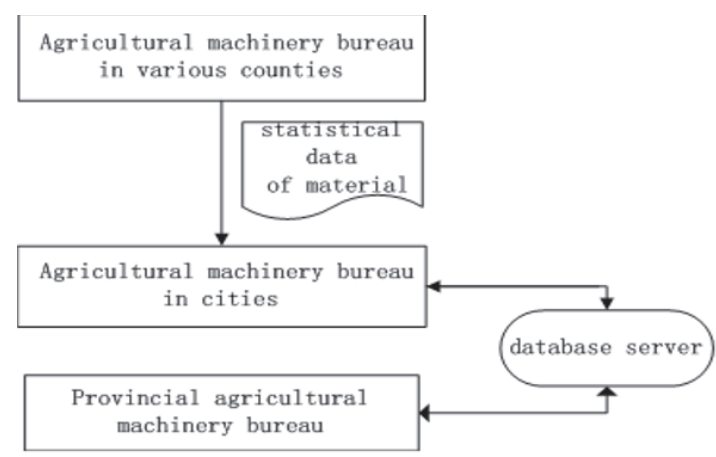

Fig.1. The flow chart of operational information

To those statistical staff who work in the county-country, they can only receive the information by traditional ways because of the grass-root units, comparative low-level application of computer, and inaccessibility of network. Thus the paper material is the basis of the overall data system.

To those staffs who work in the cities, some application on PC such as Excel is available to the statistic. Then after signed by the chief of the bureau, they can fill and submit the data on-line and mail the signed material to the provincial agricultural machinery bureau.

To those staffs who work in the provincial agricultural bureau, they have to complete the collection of the all the statistical material after the new statistical material is generated by the system automatically and provide the result of statistic and analysis to the chief leader to make decision.

\section{SYSTEM DESIGN}

\subsection{Function design}

The overall plan was made. The subsystem was divided into smaller subsystems while designing the system. To get a satisfying system with a 
better structure, we have to optimize the system according to some principles such as coupling rule and cohesion rule among modules.

Figure 2 is the physical function chart of farm machinery statistic system.

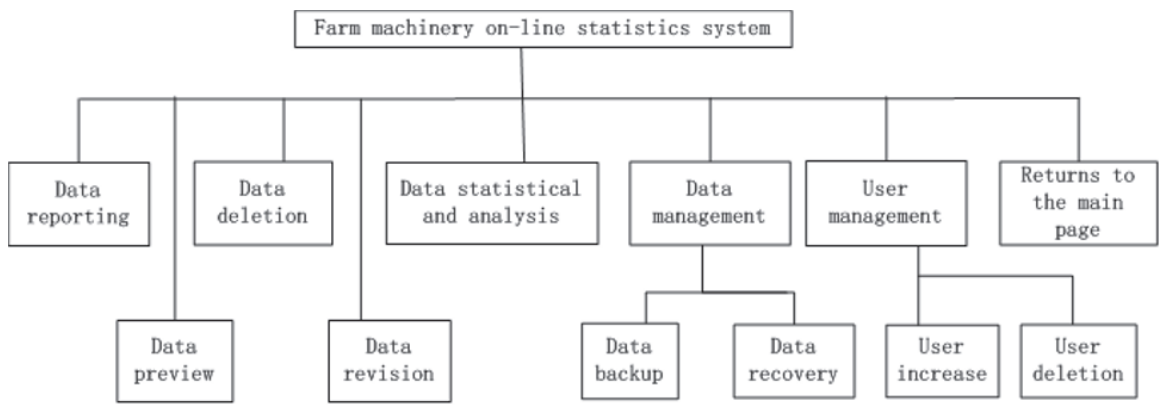

Fig .2. Physical function chart of agriculture machinery statistic system

The data administration module and the user administration module are only available to the provincial agricultural machinery bureau staff. As the super administrator, the staff shoulders the responsibility of maintaining and administrating the data, which is of highly importance to the reliability of the system. This setting will prevent the data from destruction on occasion of incorrect manipulation or some interference. At the same time, the staff can add or delete any user and give them varies of management authority.

\subsection{System development platform}

Considering that the ASP technology developed by Microsoft Company is comparatively early with a mature operation and wide spread, ASP.net is chosen to be the compiling environment of the system. Thus the platform will be Windows 2000 Server + IIS 5.0 + ASP.net.

ASP is the short form of Active Server Page. It is a script language based on Web. Seen as the integration of HTML, Script and CGI, it provides with a much more flexible programming than HTML, a higher security than Script and a higher efficient than CGI (Yuying et al., 2002). Figure 3 shows the working principle of ASP

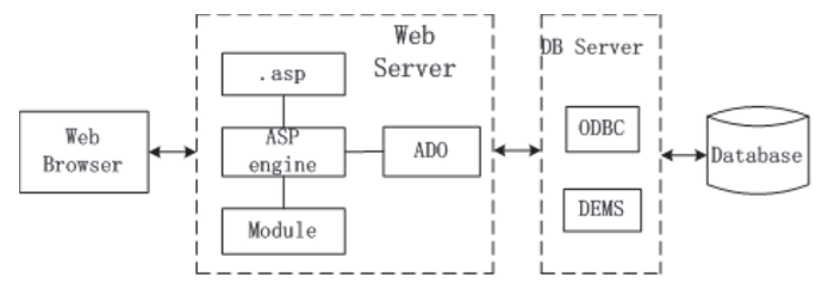

Fig.3. The chart of the work principle of ASP 


\section{THE REALIZATION OF THE MAIN FUNCTION}

\subsection{The realization of the data statistical and analytical function of the civic bureau}

After the administrator of the agricultural machinery of the civic bureau enters the system, he can manage the data in the interface. Statistical analysis is one of the important functions. Because of the large quantity of the statistical data, we divide the database into 17 data tables according to the requirement of the Agricultural Machinery Office of the Department of Agriculture. Thus the system can easily do the statistical and analytical job of any table.

When the civic administrator selects the statistics \& analysis, he will be asked to select the table to do. Then he will enter the main interface. If the chart analysis is chosen, he will get the yearly statistical chart of the table. There is the list box with several fieldnames under the chart for the administrator to choose, and then the yearly column diagram in accordance with the fixed fieldname is on show automatically.

Figure 4 is a column chart of an agricultural machinery overall power analysis of 3 years exemplified by the Agricultural Machinery Bureau of Nanjing.

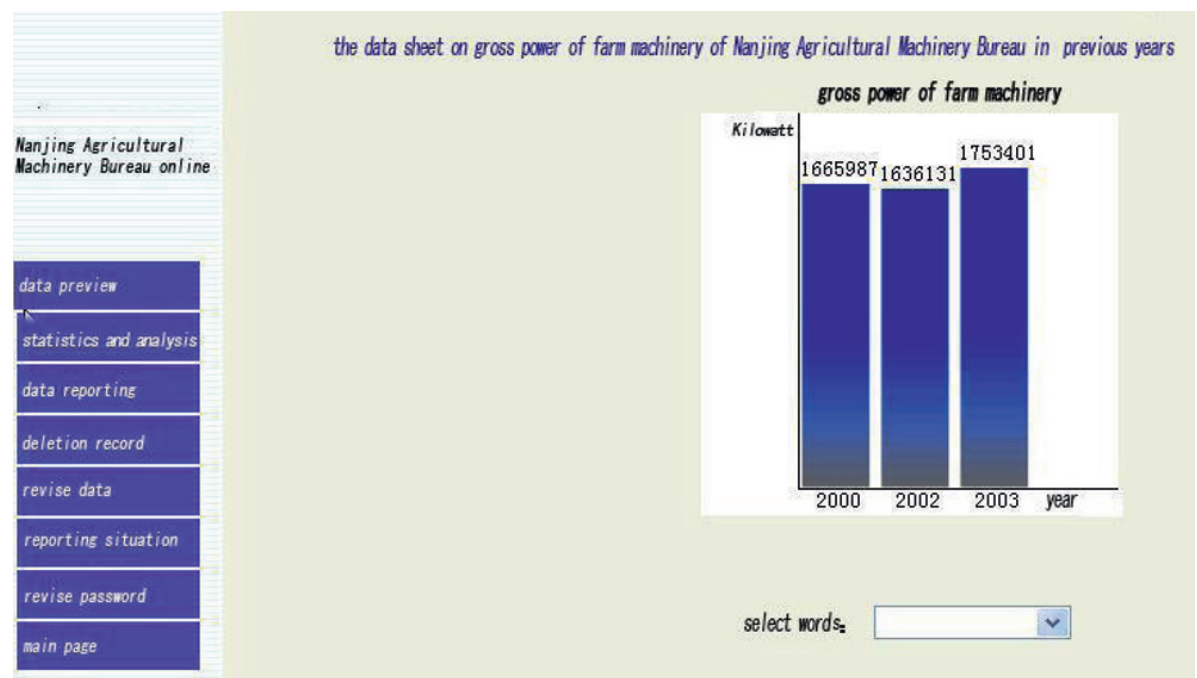

Fig .4. The example chart of statistics and analysis 


\subsection{The realization of the data reporting function of the civic bureau}

With so many data tables to be reported, the data reporting on-line will cost around a month. The administrator must know the report status of all of the tables and then give directions to the users of the system. The function of reporting aims mainly at the convenience for the administrator to examine the overall situation of reporting such as the exact time, the concrete items of each table. While designing the system, the 17 tables will be searched, and then demonstrated the reporting in the form of table. Figure 5 is the realization:

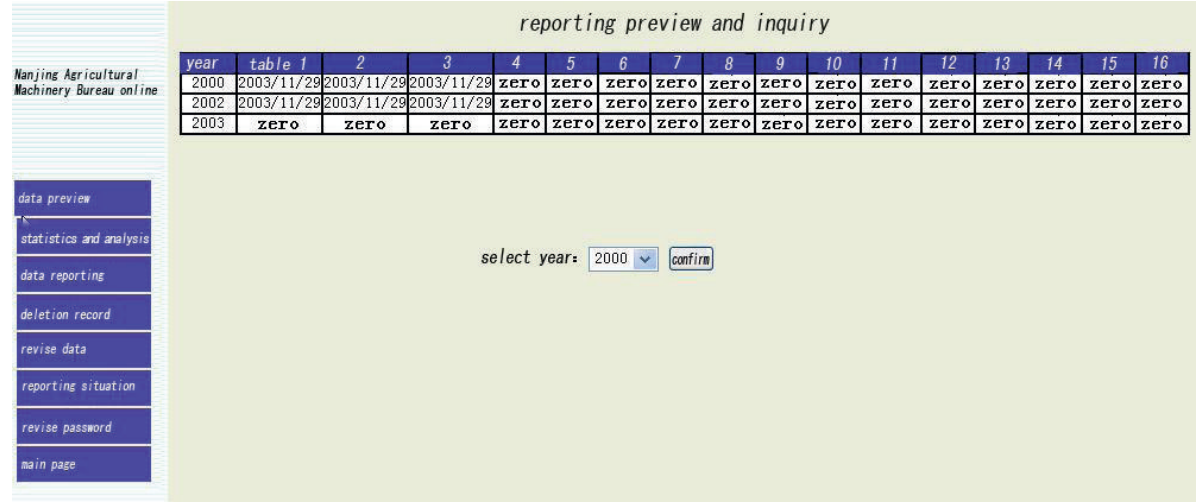

Fig.5. The example chart of reporting data

There is a drop-down list box under the table to choose. After selecting the certain year and clicking the button, you will see the reporting situation in certain year.

\subsection{The realization of the statistical and analytical function in provincial bureau}

Statistical and analytical functions are important aspects of the management for the provincial agricultural machinery bureau. Always there are two statistical methods, namely transverse and lengthways. Transverse style requires a statistical work on every amount of the 13 cities in a certain year while lengthways style requires a statistical work on every unit in different time span. At the same time, it also has to analyse the exact situation of reporting in all the cities. There is a drop-down button for the administrator to select a table to continue, then will enter the corresponding interface after the clicking. There is a chart statistical button at the bottom of the interface. The administrator will be requested to select the abscissa value after clicking the button and then he can choose a certain region or year in 
the corresponding drop-down list box. After clicking the button the statistical work will be done by the chosen abscissa. Supposing the agricultural machinery total power table is chosen, with the interface as the result in Figure 6:

\begin{tabular}{|c|c|c|c|c|c|c|}
\hline \multirow[t]{4}{*}{ Manager online } & \multicolumn{6}{|c|}{ gross power of farm machinary } \\
\hline & area & year & $\begin{array}{l}\text { the power of diesel oil } \\
\text { ensine (ki lowatt) }\end{array}$ & $\begin{array}{l}\text { the power of gasol ine } \\
\text { engine (ki lowatt) }\end{array}$ & $\begin{array}{l}\text { the power of electric } \\
\text { motor (kilowatt) }\end{array}$ & \begin{tabular}{|l} 
Eross power of farm \\
machinaer (kilowatt)
\end{tabular} \\
\hline & Changzhou & 2002 & 768629 & 69346 & 812509 & 1650484 \\
\hline & Nanjing & 2002 & 990541 & 41140 & 604450 & 1636131 \\
\hline \multirow{2}{*}{ data previear } & Wuxi & 2002 & 728155 & 152161 & 728713 & 1609029 \\
\hline & Xuzhou & 2002 & 3147172 & 39069 & 835223 & 4021464 \\
\hline \multirow{2}{*}{ statistics and analysis } & Suzhou & 2002 & 1245568 & 111961 & 1040450 & 2397979 \\
\hline & Nantong & 2002 & 1381720 & 144835 & 1071020 & 2597575 \\
\hline \multirow[t]{2}{*}{ reparting situation } & Huaian & 2002 & 2009991 & 23432 & 388225 & 2421648 \\
\hline & Yancheng & 2002 & 2606413 & 223329 & 983048 & 3812790 \\
\hline \multirow[t]{2}{*}{ increases the new user } & Yangzhou & 2002 & 1081417 & 39202 & 619697 & 1740316 \\
\hline & Zhenjiang & 2002 & 592856 & 69720 & 540586 & 1203162 \\
\hline 'taries user's squlifications & Lianyungang & 2002 & 1612637 & 37621 & 514197 & 2164455 \\
\hline \multirow{2}{*}{ revise passarord } & Taizhou & 2002 & 1315404 & 12870 & 652363 & 1980637 \\
\hline & Suqian & 2002 & 2165739 & 18504 & 401342 & 2585585 \\
\hline data bachep & graph analysis & & & & & \\
\hline data recovery & renark: & & & & & \\
\hline main page & no submitted da & ar: & & & & \\
\hline
\end{tabular}

Fig .6. The main screen of statistics and analysis

The analytical button is stimulated in the chart to choose the chart statistical function. And the cities which have not reported the data will be listed in the memo automatically by the system. The development of various regions can be easily seen on the transverse chart (Hua et al., 2005) . Figure 7 is the chart of different cities comparing.

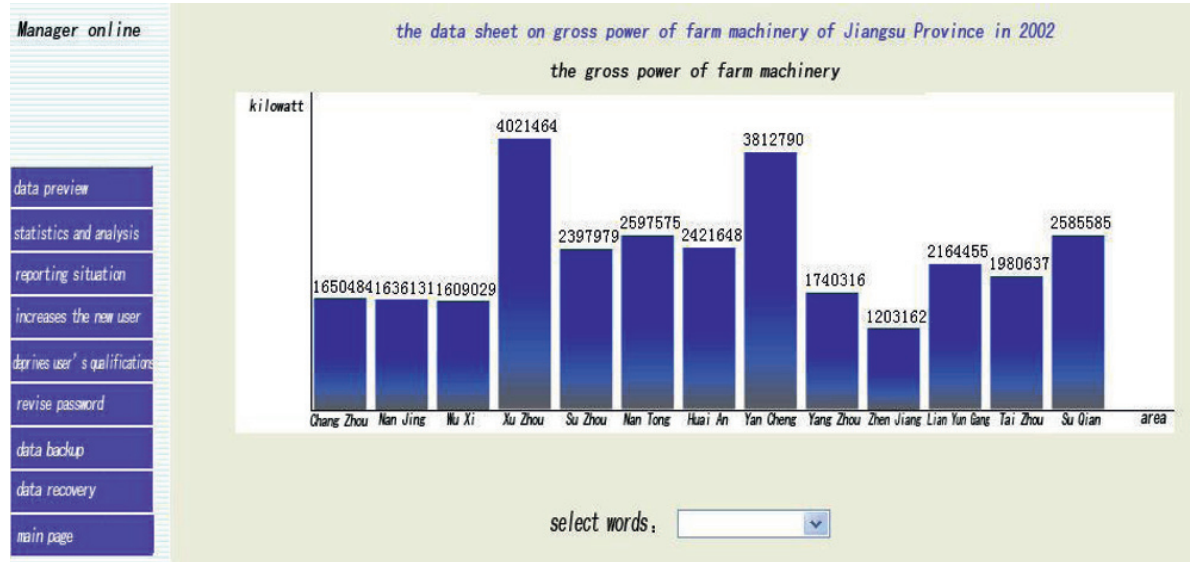

Fig .7. Example chart of statistics and analysis

The administrator can select different fields in the drop-down list box. Then the chart will be given automatically in the form of column diagram to show the differences between cities. 
The difference between various years in the certain region can be easily showed by the column diagram. There are two choices in the list box, namely region and year. When the region is chosen, the statistical chart in time span in accordance with the year will be shown as well as the reporting status in the year. The statistical button is available and it can provide with a statistical chart. Figure 8 is the example of the lengthways style.

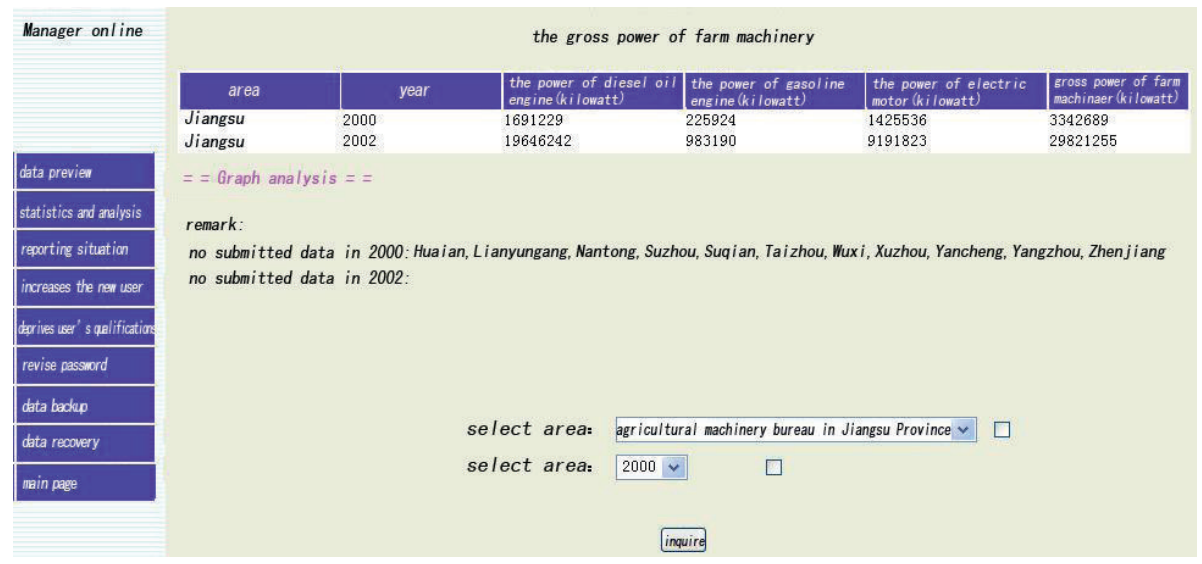

Fig.8. Example chart of the lengthways style

There is a drop-down list box including region and year choices in the analytical chart to make a multifactor output.

\section{CONCLUSION}

With the development of the computer and communication technology, the management information system based on WEB database has been widely used in many industries. According to the practice of the Jiangsu provincial farm machinery management, we developed a statistical and management system based on WEB database which has received praise after the tryout in the provincial agricultural machinery bureau. But the large quantity of users belonged to the country have not been taken into consideration. With further economy development and the access to hardware as well as software, the system can be further extended to meet the need of the provincial agricultural machinery statistical and management.

\section{REFERENCES}

Guosheng Yan . The application of computer in the management of agricultural mechanization[M]. BeiJing, Qinghua University Press,1998:

He Yong Bao Yidan. The investigation on agricultural mechanization database management system[J]. Science and technology Journal. 1995,(3): 147-151. 
Hua Li,Wenqing Yin. The realization of the agricultural machinery statistical chart based on the WEB environment[J]. Journal of Anhui Agricultural Sciences. 2005,33 (8): 1395-1396.

Ruiyin He. The development of agricultural machinery management system in large and medium farms[J]. The research on agricultural mechanization. 1998,(4): 84-87.

Singh Gajendra,Pathak B. K. A decision support system for mechanical harvesting and transportation of sugarcane in Thailand[J]. Computers and Electronics in Agriculture. 1994,(11): 173-182.

Xindan Qi,Hua Li. The development of the software of statistical management system[J]. Nanjing Chemical and Industrial University Transaction. 2000,(6): 10-12.

Yuying Wang, Yangyu Ou,Chuanjiu Han. The realization of dynamic statistical chart in WEB[J]. Guilin Engineering College Transaction. 2002,22 (2): 201-203.

Zhong Yao. Distributed agricultural statistical information management system[J]. Computer and Agriculture. 1995,(3): 20-22. 